\title{
Age and Gender Differences in Motivational Manifestations of the Big Five From Age 16 to 60
}

\author{
Regula Lehmann \\ University of Zurich \\ Mathias Allemand
}

\author{
Jaap J. A. Denissen \\ Humboldt University of Berlin
}

Lars Penke

University of Edinburgh

\begin{abstract}
The present cross-sectional study investigated age and gender differences in motivational manifestations of the Big Five in a large German-speaking Internet sample $(N=19,022)$. Participants ranging in age from 16 to 60 years completed the Five Individual Reaction Norms Inventory (FIRNI; Denissen \& Penke, 2008a), and two traditional Big Five measures. Age differences were found suggesting that mean levels of neuroticism and extraversion are negatively associated with age, whereas agreeableness and conscientiousness are positively associated. Openness to experience demonstrated a curvilinear association with age, with the highest mean levels in midlife. Gender differences were found suggesting that women, on average, have higher levels of neuroticism, extraversion, and agreeableness, while men are more open to experience. Neither the main effect of gender nor Age $\times$ Gender interactions were significant in the case of conscientiousness. In comparison to the 2 traditional Big Five measures, age differences in the motivational manifestations of the Big Five as assessed by the FIRNI were more pronounced, which might be explained by the greater developmental plasticity of flexible motivational processes or the intraindividual phrasing of the items of the FIRNI, compared to the kinds of behavioral descriptions that are emphasized in traditional Big Five items. The further study of such motivational processes might contribute to a better understanding of personality development.
\end{abstract}

Keywords: motivational reaction norms, Big Five, age differences, adolescence, adulthood

The Big Five personality traits have been proposed to summarize individual differences in enduring patterns of thoughts, feelings, and behaviors (John, Naumann, \& Soto, 2008; McCrae \& Costa, 2008). Recently, Denissen and Penke (2008a) emphasized motivational manifestations of the Big Five by conceptualizing the Big Five as enduring individual differences in motivational reactions to circumscribed classes of environmental stimuli. From an action-theoretical point of view, such motivational underpinnings are highly important, as they can be considered as a driving force

This article was published Online First April 30, 2012

Regula Lehmann, Department of Psychology, Division of Gerontopsychology, University of Zurich, Zurich, Switzerland; Jaap J. A. Denissen, Department of Psychology, Division of Personality Development, Humboldt University of Berlin, Berlin, Germany; Mathias Allemand, Department of Psychology, Division of Gerontopsychology, University of Zurich; Lars Penke, Department of Psychology, Center for Cognitive Ageing and Cognitive Epidemiology, University of Edinburgh, Edinburgh, Scotland.

Preparation of this article was supported by the Swiss National Science Foundation (Grant SNSF-100014-120625). Regula Lehmann is a predoctoral fellow of the International Max Planck Research School on the Life Course: Evolutionary and Ontogenetic Dynamics. We thank Patrick Hill for helpful comments on earlier drafts.

Correspondence concerning this article should be addressed to Regula Lehmann, who is now at Psychiatric University Hospital, Lenggstrasse 31, Postfach 1931, 8032 Zürich, Switzerland. E-mail: regula.lehmann@ gmail.com of self-directed development. The present study aimed to test hypotheses with respect to age and gender differences in the motivational manifestations of the Big Five from age 16 to 60 . We present a broad theoretical rationale for the hypotheses based on socioemotional and/or biological accounts of development. Previous studies on personality traits (including the Big Five) using established instruments have demonstrated differences in age (cf. Roberts, Wood, \& Caspi, 2008) and gender (e.g., Feingold, 1994) across the entire life span. However, it is not clear whether the motivational manifestations of the Big Five demonstrate similar age and gender patterns. This is an important lacuna in the literature because it ignores the demonstrated importance of goals and motivation for life-span development (Heckhausen, Wrosch, \& Schulz, 2010). To investigate the importance of such a motivational perspective, the present study aimed to compare age and gender trends in the Big Five, as measured with the Five Individual Reaction Norm Inventory (FIRNI), with two established measures of the Big Five.

Denissen and Penke's (2008a) conceptualization of the Big Five as individual differences in motivation reactions to circumscribed classes of environmental stimuli is based on the behavioral ecological concept of reaction norms (for details on the conceptualization of the Big Five, see the Theoretical Rationale). An individual reaction norm describes the disposition of an organism to exhibit a specific class of behaviors, dependent on the environmental situation (Dingemanse, Kazern, Réale, \& Wright, 2010; Nettle \& Penke, 2010; Penke, Denissen, \& Miller, 2007a, 2007b). 
Furthermore, Denissen and Penke (2008a) included motivational components of personality traits in their model (see also Costa \& McCrae, 1988; Winter, John, Stewart, Klohnen, \& Duncan, 1998). According to Murray's (1938) classical theory, personality is driven by psychological needs, which was empirically confirmed by Costa and McCrae (1988) in a factor-analytical study. The advantage of conceptualizing traits as motivational constructs is that it explicitly recognizes traits as interacting with environmental features, which nicely dovetails with the assumptions of contemporary developmental research that life-span development is the product of the interaction between individuals and their environmental context (Baltes, Staudinger, \& Lindenberger, 1999). To measure these motivational manifestations of the Big Five, Denissen and Penke (2008a) developed the FIRNI and demonstrated empirical evidence for its reliability and validity. The current study extends this line of research by looking for age differences in these motivational manifestations of personality.

\section{Age Differences in the Big Five}

Research on personality trait development demonstrated systematic age differences and age-related changes in the mean levels of personality traits in adolescence and adulthood (e.g., Allemand, Zimprich, \& Hendriks, 2008; Klimstra, Hale, Raaijmakers, Branje, \& Meeus, 2009; Lucas \& Donnellan, 2009; Lüdtke, Trautwein, \& Husemann, 2009; McCrae et al., 2000; Roberts, Walton, \& Viechtbauer, 2006; Srivastava, John, Gosling, \& Potter, 2003). The general picture that emerges from both cross-sectional and longitudinal research suggests that adolescents tend to increase in extraversion and openness to experience and tend to decrease in neuroticism. In adolescence, some gender differences have been reported in mean level development. For example, Klimstra et al. (2009) showed an increase in emotional stability in boys aged 16 to 20, while girls increased in extraversion and openness to experience. No gender-specific development was found for agreeableness in this study: Girls as well as boys showed an increase in agreeableness during the age period of 16 to 20 . In contrast, age differences in personality seem to be more consistent across gender in adulthood. Specifically, research indicates that from emerging adulthood through middle age, conscientiousness and agreeableness show positive age trends, while neuroticism demonstrates a negative trend, and extraversion and openness to experience show flat trends in both women and men. For example, Soto, John, Gosling, and Potter (2011) tested hypotheses about age differences in a large cross-sectional Internet sample $(N=1,267,128$; ages $10-65)$ and found positive trends for mean levels of agreeableness and the self-discipline facet of conscientiousness. Neuroticism showed negative age trends across early adulthood and middle age, while extraversion showed a small negative association during emerging adulthood and a relatively flat trend from young adulthood through middle age. Analysis of openness to experience revealed a positive age trend in mean levels across emerging adulthood that decelerates in middle age.

Several theoretical perspectives are consistent with age-related changes in personality during adolescence. Different developmental theories conceive this phase of life as a significant stage for social and personality development, with biological, cognitive, and social definitional changes (i.e., changes in the legal or social standing of the adolescent) as defining features (cf. Collins
\& Steinberg, 2006). First, there is growing evidence that maturational brain processes are continuing through adolescence (Giorgio et al., 2010; Paus, 2005), which might have an impact on personality development. Second, newly acquired cognitive structures like improvements in self-regulation might influence the way adolescents interact with their environment (Piaget, 1983; Tau \& Peterson, 2010), which in turn might be associated with changes in personality in this phase of life (cf. Roberts et al., 2006). Third, social transitions are thought to bring along new social roles that may serve as focal points for personality trait development (Roberts \& Wood, 2006). According to Roberts (2007), growing up can indeed be construed as a process in which children and adolescents conform to a series of normative expectations from parents, friends, and society at large.

Two opposing theories have been used to explain age differences in personality traits across the whole life span. On the one hand, age-related mean-level differences have been explained by invoking species-universal genetic influences and intrinsic maturation processes (e.g., McCrae et al., 2000). According to some proponents of this theory, traits reach maturity around age 30, with only small changes after age 30 (Terracciano, Costa, \& McCrae, 2006). On the other hand, personality trait development has been explained by the complex interplay between biological processes and individual reactions to changes in the environment (e.g., Baltes et al., 1999; Caspi \& Roberts, 2001). This perspective also suggests that changes in personality can occur past age 30 and makes no explicit prediction regarding differences in amounts of change before and after age 30 (cf. Lucas \& Donnellan, 2009; Srivastava et al., 2003).

\section{Gender Differences in the Big Five}

Studies on gender differences in personality traits in adolescence and adulthood reported modest effects with partly inconsistent results across studies (e.g., Chapman, Duberstein, Sörensen, \& Lyness, 2007; Costa, Terracciano, \& McCrae, 2001; Donnellan \& Lucas, 2008; Schmitt, Realo, Voracek, \& Allik, 2008; van Aken, Denissen, Branje, Dubas, \& Goossens, 2006). In general, women tend to score higher on neuroticism and agreeableness, whereas gender differences in the other Big Five traits have been either inconsistent or of negligible magnitude. Furthermore, the described gender differences seem to be consistent across different ages in the life span (Chapman et al., 2007). Finally, Costa et al. (2001) showed that gender differences are modest in magnitude, consistent with gender stereotypes, and replicable across 26 cultures.

Biological, sociocultural and biosocial models might explain gender differences in personality traits (cf. Feingold, 1994). For example, biological theories point to hormonal differences and their effects on mood and personality, and to sex-linked differences in genetic predispositions to psychopathology (Costa et al., 2001; Jang, Livesley, \& Vernon, 1998). Evolutionary psychology implies that gender differences are originated through a causal process of sexual selection (Buss, 1995). Men and women differ, in this view, in domains in which they have faced different adaptive problems over human evolutionary history. In contrast, the sociocultural model of gender differences posits that social and cultural factors directly produce gender differences in personality traits (e.g., Eagly, 1987). Finally, integrating social and biological 
approaches, Schmitt et al. (2008) indicated that genetic personality predispositions of men and women are sensitive to certain contextual factors (e.g., environmental stress) in ways that differentially activate or suppress these predispositions.

\section{Theoretical Rationale of the Present Study}

The main objective of the current cross-sectional study was to examine age and gender differences in motivational manifestations of the Big Five using data from a large German-speaking Internet sample. To map out the patterning of age and gender differences in more detail, we used regression models with curvilinear effects. In line with Denissen and Penke's (2008a, p. 1298) theoretical call to arms, we present the theoretical rationale for our hypotheses on the basis of socioemotional and/or biological explanations. A second objective is to extend our analysis by comparing age and gender patterns in the Big Five traits as assessed by different measures. Specifically, we explore age and gender differences in the Five Individual Reaction Norm Inventory (FIRNI; Denissen \& Penke, 2008a), which is based on the motivational approach discussed above, and two traditional measures of the Big Five. This is the first study investigating age and gender differences in mean-level scores obtained with an instrument that assesses personality traits from a motivational perspective.

The theoretical rationale is organized as follows: For every Big Five trait we present hypotheses about (a) age differences in the FIRNI, (b) gender differences in the FIRNI, (c) Age $\times$ Gender interactions in the FIRNI, and (d) hypotheses about differences between motivational and traditional conceptualizations of the Big Five.

\section{Neuroticism}

In our motivational framework, neuroticism reflects individual differences in people's sensitivity to signs of social exclusion (Denissen \& Penke, 2008a, 2008b).

1. From a developmental task perspective (Havighurst, 1981), it can be assumed that adolescents are more sensitive to social exclusion than adults. Adolescence is a period when issues of acceptance by peers and romantic partners are particularly salient as adolescents work on the developmental tasks of autonomy and identity (Downey, Bonica, \& Rincon, 1999). Rejection sensitivity might decrease with age as more experience is acquired in managing romantic relationships and friendships. Related to this idea is the pronounced need of adolescents to fit into their peer group (Steinberg \& Monahan, 2007). A strong need to fit in and need for social approval have been linked to depressive symptoms (Rogers et al., 2009), which are associated with higher neuroticism (Kercher, Rapee, \& Schniering, 2009). Moreover, research has shown that emotional autonomy increases with age (Steinberg \& Silverberg, 1986). Finally, change of schools and associated change of classroom environments and social relationships during early adolescence might promote sensitivity to social exclusion which, in turn, might increase the need to reestablish one's place in the social hierarchy (Eccles et al., 1993). In later adolescence, stability in the education environment might then facilitate a subsequent decrease in sensitivity to social exclusion. On the basis of these arguments and previous research, we assumed a negative association of neuroticism with age, particularly during adolescence and younger adulthood.
2. In terms of gender differences, we expected women to be somewhat more neurotic than men. In social relationships, women tend to value emotional intimacy more than men (e.g., Belle, 1991) and are more focused on positive reciprocity (getting along), while men are more focused on negative reciprocity (getting ahead; Maccoby, 1990).

3. Scattered empirical results suggest an Age $\times$ Gender interaction effect in neuroticism, with women declining substantially throughout adulthood and men declining more modestly (e.g., Srivastava et al., 2003). Overall, however, meta-analytic findings show an almost complete lack of statistically significant relationship between gender and mean-level change in neuroticism (Roberts et al., 2006). Moreover, making normative commitments to conventional social institutions like work and family might support a positive development in traits associated with psychological maturity, such as sensitivity to social exclusion, similarly in both women and men (see also Roberts \& Wood, 2006). Therefore, we expected no age by gender interaction effect for neuroticism.

4. We expected a more accentuated negative association between age and neuroticism when measured with the FIRNI compared to the traditional measures. While neuroticism in FIRNI is conceptualized as sensitivity to social exclusion, traditional measures of neuroticism focus on negative affectivity in general. It can be speculated that, especially in late adolescence and early adulthood, sensitivity to social exclusion shows a strong negative association with age due to an increased confidence regarding the interaction in social relationships. Partial support for this claim comes from research suggesting a decrease in social anxiety across adolescence (Ingles, La Greca, Marzo, Garcia-Lopez, \& GarciaFernandez, 2010).

\section{Extraversion}

Denissen and Penke (2008a) conceptualized extraversion as individual differences in the activation of the reward system in social situations.

1. During adolescence, activation of the reward system in social situations might be positively associated with age due to salient developmental tasks regarding the establishment of social relationships with peers. Specifically, adolescents have to learn to establish close relationships and seek out exchanges that support a sense of self-identity, sensitivity for the needs of others, and maintenance of mutually oriented relationships with peers (Hartup \& Stevens, 1997). In contrast, in adulthood individuals may even strive to reduce the absolute size of their social network to allow a focus on a more limited number of emotionally rewarding relationships (Carstensen, Isaacowitz, \& Charles, 1999). On the basis of these reflections and empirical results, one may expect a positive association of extraversion with age during adolescence and a negative association during adulthood.

2. Regarding gender differences, research has found higher values in affiliation motivation and sociability in women compared to men (Czeschlik \& Nürk, 1995; Mazur, 1989; Wong \& Csikszentmihalyi, 1991). From a biological perspective, this genderdifferential pattern might reflect females' role in nursing and defending offspring in the evolution of our species. Taylor et al. (2000) characterized the female responses to stress as "tend-andbefriend," involving caring for offspring, joining social groups to reduce vulnerability, and contributing to the development of social 
groupings, especially those involving female networks, for the exchange of resources and responsibilities. The neuropeptide oxytocin is especially important in female reproduction, and its effects on human affiliation have been ascribed to both attenuation of anxiety and activation of reward systems (Campbell, 2008). In line with theory and research, one might expect women to be more extraverted than men. On the other hand, extraversion is related to greater sexual promiscuity, which should be more adaptive for men than for women according to evolutionary theories (Schmitt, 2004). This line of reasoning could provide an alternative account for greater extraversion in men.

3. It might be argued that during adolescence the developmental tasks of learning to establish close relationships and other exchanges increase equally in importance in girls and boys. Furthermore, both women and men might strive to reduce the absolute size of their social network to allow a focus on a more limited number of emotional rewarding relationships in adulthood. Therefore, and on the basis of meta-analytic results (Roberts et al., 2006), we did not predict an Age $\times$ Gender interaction effect for extraversion.

4. It might be suggested that traditional Big Five measures compared to the FIRNI show less negative association between extraversion and age during adulthood due to their main focus on positive affect. For example, Charles, Reynolds, and Gatz (2001) reported stability in positive affect across young and middle adulthood. Moreover, Costa et al. (1987) suggested that positive affect is rather stable and less responsive to changing life circumstances.

\section{Openness to Experience}

In the current motivational framework, openness to experience is conceptualized as the reward value of engaging in intellectual activity.

1. From a biological perspective, recent studies of brain development suggest continued brain maturation and related increases in cognitive abilities until the age of 25 (Casey, Tottenham, Liston, \& Durston, 2005; Giorgio et al., 2010; Schmithorst, Wilke, Dardzinski, \& Holland, 2005). For example, maturation of the white matter is associated with increases in psychometrically measured intelligence. IQ scores, in turn, have been related to openness to experience (McCrae \& Costa, 1997). In adolescence and young adulthood, brain maturation is in general paralleled by extensive education experiences. Education and school environment might additionally stimulate openness to experience (Cacioppo, Petty, Feinstein, Blair, \& Jarvis, 1996). In contrast, late middle adulthood reflects a time where individuals are relatively "set in their ways." Only a few individuals in late middle adulthood might experience new challenges in work and family life or enroll in an educational institution. For example, for a sample of highly educated professionals, Karp (1987) reported that the time period between 50 and 60 years of age brought relatively little job change, and work novelty began to diminish. Less novelty and cognitive decline combined might result in a negative association of the reward value of engaging in intellectual activity with age in late middle adulthood. In line with this reasoning and previous personality development research (Roberts et al., 2006), we expected a pronounced positive association of openness with age during adolescence and young adulthood, and a negative association in late middle adulthood.
2. With respect to gender differences, men and women have been characterized in terms of different cognitive styles (objective evaluation of experience vs. subjective evaluation of experience; Gridley, 2006). Furthermore, Costa et al. (2001) reported higher mean scores for men in the openness facet of openness for ideas, which can be mapped onto Denissen and Penke's (2008a) motivational conceptualization of openness (since ideas can be seen as both the input and the result of intellectual activity). Because preferences and choices are sensitive to social conditions, it is difficult to determine whether biologically based sex differences in cognitive preferences, motives, and styles also exist (Ceci, Williams, \& Barnett, 2009; Spelke \& Grace, 2006). Although the gender difference in the reward value of cognitive activity may not be innate, on the basis of the results of previous empirical studies we expected men to be more open to experience than women.

3 . Both girls and boys show continued brain maturation and related increases in cognitive abilities until the age of 25 (e.g., Tamnes et al., 2010). Furthermore, both women and men can be thought of as more set in their ways in late middle adulthood. In line with this reasoning and previous research (Roberts et al., 2006), we did not expect an Age $\times$ Gender interaction for openness to experience.

4. For the traditional Big Five measures we expected a positive association between openness to experience and age in adolescence and rather small age effects in adulthood. In contrast, for the FIRNI we expected a positive association between openness and age during adolescence and young adulthood, and a negative association in late middle adulthood (i.e., curvilinear change). We suggest that curiosity in general is rather typical for adolescence, whereas enjoying intellectual activity might still show a positive association with age during young adulthood. Moreover, we assume a negative association of reward value of engaging in intellectual activity with age in late middle adulthood as part of the decline in cognitive ability and novelty, whereas curiosity in general might be thought of as relatively stable across adulthood (Roberts et al., 2006).

\section{Agreeableness}

Agreeableness has been conceptualized as individual differences in the motivation to cooperate in resource conflicts (Denissen \& Penke, 2008a).

1. Regarding age differences in cooperative behavior, Szolnoki, Perc, Szabo, and Stark (2009) showed in a complex version of the prisoner's dilemma game that age influences the evolutionary process of strategy adoption. Specifically, they suggested that older individuals have had more possibilities to detect the (supposedly) higher pay-off of cooperative strategies, which explains why they cooperate more frequently. On the basis of these results, we expected adolescents and younger adults to be less agreeable than middle-aged adults.

2. Previous research suggests that women, on average, are more cooperative than men (Solnick, 2001), particularly when other women are involved in the social exchange situation (Wischniewski, Windmann, Juckel, \& Brüne, 2009). This pattern can be partly explained by gender-related differences in sex hormones and bonding hormones (Burnham, 2007; Kirsch et al., 2005; Kosfeld, Heinrichs, Zak, Fischbacher, \& Fehr, 2005; Wischniewski et al., 2009). Furthermore, in evolutionary terms, 
the above-mentioned principle of tend-and-befriend (Taylor et al., 2000) might not only explain the gender differences in extraversion but also account for gender differences in agreeableness. Hence, we expected women to be more agreeable than men.

3. Getting more cooperative across adulthood can be linked to the maturity principle reported above for neuroticism (see Roberts \& Wood, 2006). Acting more cooperatively might help both women and men to fulfill socially important roles. Therefore, on the basis of meta-analytic results (Roberts et al., 2006), we did not expect an Age $\times$ Gender interaction effect for agreeableness.

4. For agreeableness, we do not suggest accentuated differences between the FIRNI and the traditional measures. As noted above, we expected a positive association between the motivation to cooperate in resource conflict and age. Similarly, previous research (e.g., Roberts et al., 2006) suggests a positive association between agreeableness as measured with traditional Big Five instruments and age.

\section{Conscientiousness}

Denissen and Penke (2008a) conceptualized conscientiousness as individual differences in the tenacity of goal pursuit under distracting circumstances.

1. From a biological perspective, a major component of the neurological development during the transition from adolescence to young adulthood pertains to growth in brain regions associated with cognitive control (Steinberg, 2007). While anatomical brain maturational changes during adolescence and young adulthood might enhance the tenacity of goal pursuit under distracting circumstances, middle-aged adults might further improve their tenacity of goal pursuit due to better goal setting and goal attainment strategies (Riediger, Freund, \& Baltes, 2005). Furthermore, Rubia et al. (2006) demonstrated progressive age-related neurocognitive specialization of cognitive control during adulthood. In this study, more mature networks in frontal, parietal, and cingulate brain regions seemed to support the performance in cognitive control. In line with these results and previous research on personality development, we therefore expected a positive association of conscientiousness with age from adolescence to middle adulthood.

2. In terms of gender differences, Luszczynska, Diehl, Gutiérrez-Doña, Kuusinen, and Schwarzer (2004) did not find differences in attention control in goal pursuit, which indicates gender similarity with respect to tenacity of goal pursuit. Similarly, Garavan, Hester, Murphy, Fassbender, and Kelly (2006) did not find gender differences in the performance of inhibitory control, although differences in regional brain activation were found. It can be assumed that although men and women have faced different adaptive problems, the need for goal-directed behavior across a broad range of activities inhibited the evolution of gender differences in tenacity (Ardila, 2008). On the basis of this assumption and empirical results, we did not expect gender differences for conscientiousness.

3. A positive association of tenacity of goal pursuit under distracting circumstances with age can be linked to becoming more functionally mature with age. Increases in this trait across adulthood might be equally important for women and men because people higher on this trait tend to be more effective in the tasks of social development (see Roberts \& Wood, 2006). On the basis of these arguments and meta-analytic results (Roberts et al., 2006) we did not expect an Age $\times$ Gender interaction for conscientiousness.
4. We do not expect accentuated differences between age trends in conscientiousness as measured with the FIRNI and traditional Big Five instruments. In line with the maturity principle (Roberts \& Wood, 2006), it can be suggested that tenacity of goal pursuit under distracting circumstances as well as variables like competence and dutifulness might serve to facilitate functioning in society and therefore should be positively associated with age.

\section{Method}

\section{Participants}

The participants were 19,022 German-speaking Internet users who completed the FIRNI online. The average age of participants was 24.94 years ( $S D=10.09$, range 16 to 60 years, $M d n=21$ ) and $69.1 \%$ were women. There was a broad range in educational attainment: $37.4 \%$ reported that they had completed basic education (German Hauptschule and Realschule) as their highest level of education, $42.7 \%$ had a high school degree (German Abitur), and $14.2 \%$ had graduated from university; 722 participants $(3.8 \%)$ reported that they had not completed their education. However, this group was very young in average $(M=18.18, S D=5.39)$ and mostly consisted of individuals who had not completed formal schooling yet. Of the participants who completed the FIRNI, a subsample of 17,315 participants $(91.03 \%)$ completed the subsequent Personality Adjective Scales (PAS), and 16,500 participants $(86.74 \%)$ completed the Big Five Inventory (BFI), which was presented at the end of the questionnaire. No significant differences were observed between the subsamples and the total sample with regard to motivational manifestations of the Big Five, and age and gender distribution.

\section{Procedure}

The data were collected using the portal for online research of the Psychology Department of the Humboldt University of Berlin (http://www.psytests.de/). This website hosts several surveys and personality measures. In return for their participation in the present study, participants received a personality profile (feedback) after completion of the study.

\section{Measurement}

Five Individual Reaction Norms Inventory (FIRNI). The FIRNI was developed to measure enduring individual differences in people's motivational reactions to circumscribed classes of environmental stimuli (Denissen \& Penke, 2008a). The FIRNI captures motivational tendencies with items that are framed in a way that differs from traditional inventories (while at the same time tapping into the same latent factor space as traditional Big Five measures). This measure consists of 10 items for each Big Five domain (e.g., for neuroticism: "When I meet with friends I sometimes have the feeling that they talk badly about me afterward"; for extraversion: "Talking with other people motivates me and brings out the best in me"; for openness to experience: "I enjoy thinking of new ways to solve problems"; for agreeableness: "I would rather share something than to compete with other people for having it all myself"; for conscientiousness: "When I have set myself a goal I pursue it very persistently"; the underlying moti- 
vational component is somewhat more implicit here, tapping into a valuation of long-term goal pursuit and an intolerance of goal distractions). The items are answered on a 5-point Likert-type rating scale, ranging from 1 (not at all) to 5 (completely). Alpha reliabilities in the present sample were $\alpha=.80$ for neuroticism, $\alpha=.90$ for extraversion, $\alpha=.82$ for openness to experience, $\alpha=$ .82 for agreeableness, and $\alpha=.86$ for conscientiousness.

Big Five Inventory (BFI). The BFI is designed to efficiently measure the core aspects of each Big Five domain (John, Donahue, $\&$ Kentle, 1991; John et al., 2008). We used the German version of the BFI (Lang, Lüdtke, \& Asendorpf, 2001). The BFI consists of 44 items and includes short phrases based on the trait adjectives known to be prototypical markers of the Big Five. The items are rated on a Likert-type scale ranging from 1 (disagree strongly) to 5 (agree strongly). In the present sample, the internal reliability coefficients were $\alpha=.85$ (neuroticism), $\alpha=.90$ (extraversion), $\alpha=.84$ (openness to experience), $\alpha=.78$ (agreeableness), and $\alpha=.86$ (conscientiousness).

Personality Adjective Scales (PAS). Second, we used an adjective-based measure of the Big Five based on a study by Ostendorf (1990), consisting of 60 bipolar pairs of adjectives (e.g., lazyhardworking, talkative-silent). Participants were asked to assess the extent to which the adjective pair described them in general. All adjective pairs were rated on a 6-point Likert-type scale, ranging from 1 (only the left pole applies to me) to 6 (only the right pole applies to $m e$ ). The internal consistency coefficients were $\alpha=.92$ (neuroticism), $\alpha=.95$ (extraversion), $\alpha=.86$ (openness to experience), $\alpha=.87$ (agreeableness), and $\alpha=.92$ (conscientiousness).

These three Big Five questionnaires were all developed to tap into the same latent factor space of the five broad domains of personality. However, with respect to the two traditional measures, the FIRNI is based on a different conceptualization. Moreover, all measures differ in the item format. Specifically, both of the traditional measures are based on prototypical markers of personality, with the PAS consisting of marker adjectives to measure the Big Five traits (e.g., "aloof"), and the BFI consisting of short phrases and brief behavioral descriptions (e.g., "generates a lot of enthusiasm"). By comparison, the items in the FIRNI are formulated to reflect motivational reaction norms underlying each of the Big Five personality traits (see above). Corresponding to this conceptualization, the items mostly provide a situational cue (e.g., "interacting with other people") followed by a motivational reaction (e.g., "gives me a lot of energy." As stated above, the items for conscientiousness correspond somewhat less nicely to this pattern, even though if-then contingencies are implicit in this scale as well (e.g., between goal distractions and motivational reactions to invest additional energy in goal pursuit).

\section{Structural Invariance Across Age Groups}

To compare scale scores in different age groups, the factor structure should be invariant across ages. Previous studies using traditional Big Five personality measures such as the BFI found a high degree of structural invariance across age groups (e.g., Lang et al., 2001; Soto et al., 2011; Srivastava et al., 2003). To test whether the FIRNI structure was invariant across ages, we split the sample into five age groups (16-19, 20-29, 30-39, 40-49, 50-60) and then conducted principal components analyses within each group, extracting five factors in each analysis. The Big Five personality traits clearly replicated within each age group. For each personality trait, factor congruence coefficients were then calculated between the set of factor loadings of each age group (Tucker, 1951; cf. Harman, 1976). McCrae and Costa (1997) and Davenport (1990) suggested that coefficients greater than .90 reflect strong similarity of structures. Across age groups, the average congruence coefficients were .98 for neuroticism (range: .97 to .99 ), .99 for extraversion (range: .97 to .99 ), .98 for openness to experience (range: .96 to 1.00), .99 for agreeableness (range: .98 to 1.00 ) and .99 for conscientiousness (range: .97 to 1.00). These congruence coefficients reflect a high degree of structural invariance. Finally, alpha reliabilities were computed for each of the five age groups. The reliabilities ranged from $\alpha=.77$ to $\alpha=.82$ for neuroticism, from $\alpha=.88$ to $\alpha=.90$ for extraversion, from $\alpha=.78$ to $\alpha=$ .82 for openness, from $\alpha=.77$ to $\alpha=.84$ for agreeableness, and from $\alpha=.84$ to $\alpha=.87$ for conscientiousness. The five age groups thus had very similar alpha reliabilities.

\section{Statistical Analysis}

First, all values were $z$ transformed in the full sample, so that a score of zero corresponds to the sample mean (across all age groups). Then, for all personality measures, analyses were conducted by predicting each trait from gender, age, and higher order polynomials (curvilinear) of age using hierarchical regression analysis. Specifically, we first centered age (around the full sample mean of 24.94) and then tested linear, quadratic, and cubic age effects. However, because the cubic trends were very difficult to interpret, in the following we only report the linear and quadratic trends. For the trait-level analyses, each age polynomial and its corresponding interaction with gender were included as a block in a hierarchical regression analysis, and this block was retained if it met the significance criterion of $p<.01$. Because we relied on the significance of the block as a whole as a decision rule for the regression analyses, individual predictors were sometimes retained in the final model even if they did not meet this threshold.

To facilitate interpretation and comparison of the different personality measure, we calculated $T$ scores for each personality trait score within each scale. Scores were created with participants aged 30 to 34 as a reference group, following the procedure used by Donnellan and Lucas (2008). According to this procedure, scores below 50 indicate trait levels that are lower than this reference group, whereas scores above 50 indicate trait levels that are higher than the reference group. In terms of Cohen's (1988) guidelines, a difference of $2 T$ score points represents a small effect, a difference of 5 points represents a medium effect, and a difference of 8 points represents a large effect.

\section{Results}

The results are presented as follows. In the first step, we report age and gender differences in the motivational manifestations of the Big Five. The second step involves a comparison of the age and gender effects in the motivational manifestations of the Big Five with age and gender effects as found for the two traditional measures.

\section{Age and Gender Differences in the Motivational Manifestations of the Big Five}

Table 1 displays mean and standard deviations for the raw scores by age categories and gender. Results of the regression 
Table 1

Means and Standard Deviations for the Big Five Raw Scores by Age Category, Scale, and Gender

\begin{tabular}{|c|c|c|c|c|c|c|c|c|c|c|c|c|}
\hline \multirow{2}{*}{$\begin{array}{l}\text { Age } \\
\text { group/ } \\
\text { scale }\end{array}$} & \multicolumn{2}{|c|}{ Sample size } & \multicolumn{2}{|c|}{ Neuroticism } & \multicolumn{2}{|c|}{ Extraversion } & \multicolumn{2}{|c|}{ Openness to experience } & \multicolumn{2}{|c|}{ Agreeableness } & \multicolumn{2}{|c|}{ Conscientiousness } \\
\hline & Women & Men & $\begin{array}{l}\text { Women } \\
M(S D)\end{array}$ & $\begin{array}{c}\text { Men } \\
M(S D)\end{array}$ & $\begin{array}{l}\text { Women } \\
M(S D)\end{array}$ & $\begin{array}{c}\text { Men } \\
M(S D)\end{array}$ & $\begin{array}{l}\text { Women } \\
M(S D)\end{array}$ & $\begin{array}{c}\text { Men } \\
M(S D)\end{array}$ & $\begin{array}{l}\text { Women } \\
M(S D)\end{array}$ & $\begin{array}{c}\text { Men } \\
M(S D)\end{array}$ & $\begin{array}{l}\text { Women } \\
M(S D)\end{array}$ & $\begin{array}{c}\text { Men } \\
M(S D)\end{array}$ \\
\hline \multicolumn{13}{|l|}{$16-19$} \\
\hline FIRN & 773 & 850 & 66) & 2.9 & 1) & 3. & 3 & 3. & 3.55 & 3.37 & 3.19 & 3.19 \\
\hline BFI & 5,014 & 605 & .73) & .011 & $12(0.84)$ & 3.16 & 64) & $3.69(0.66)$ & $3.44(0.68)$ & 3.39 & 65) & 3. \\
\hline PAS & & 1,719 & 92) & & $36(1.11)$ & 4.03 & 4.76 & $4.81(0.66)$ & $4.13(0.79)$ & 4.19 & 82) & \\
\hline \multicolumn{13}{|l|}{$20-29$} \\
\hline FIRNI & 4,794 & 2,327 & $2.97(0.69)$ & $2.83(0.70)$ & $3.37(0.75)$ & $3.18(0.78)$ & $3.65(0.63)$ & $3.86(0.63)$ & $3.58(0.60)$ & $3.43(0.64)$ & $3.23(0.71)$ & $3.20(0.71)$ \\
\hline BFI & 4,373 & 2,117 & $3.14(0.78)$ & $2.86(0.82)$ & $3.39(0.82)$ & $3.12(0$ & $3.78(0.63)$ & $3.76(0.63)$ & $3.49(0.63)$ & $3.43(0.63)$ & $3.36(0.67)$ & $3.16(0.69)$ \\
\hline PAS & 4,534 & 2,215 & 3.45 & $3.11(1.02)$ & $4.29(1.06)$ & $3.90(1.11)$ & $4.84(0.62)$ & $4.87(0.64)$ & $4.20(0.76)$ & $4.28(0.75)$ & $4.13(0.85)$ & $3.94(0.88)$ \\
\hline \multicolumn{13}{|l|}{$30-39$} \\
\hline FIRN & 1 & 816 & 0) & 2.66 & 3.26 & 3.1 & 3 & 3 & 8) & 3.4 & 8) & 3. \\
\hline BFI & 1,213 & 735 & $3.04(0.81)$ & $2.75(0.81)$ & $3.48(0.78)$ & $3.22(0.82)$ & $3.87(0.62)$ & $3.83(0.61)$ & $3.55(0.60)$ & $3.49(0.65)$ & $3.59(0.64)$ & $3.39(0.71)$ \\
\hline PAS & 1,249 & 766 & $3.32(1.03)$ & $3.01(1.03)$ & $4.31(1.04)$ & $3.94(1.08)$ & $4.96(0.61)$ & $5.00(0.63)$ & $4.25(0.73)$ & $4.32(0.79)$ & $4.33(0.80)$ & $4.15(0.90)$ \\
\hline \multicolumn{13}{|l|}{$40-49$} \\
\hline FIRN & 99 & 502 & 71) & & & & & & & & & \\
\hline BFI & 649 & 465 & 98 & 2.6 & 3.47 & 3.32 & 3. & 3. & 3.63( & 3.59 & .62) & $3.56(C$ \\
\hline PAS & 661 & 483 & $3.24(1.02)$ & $2.83(1.03)$ & $4.33(1.05)$ & $4.09(1.05)$ & $5.00(0.63)$ & $5.05(0.64)$ & $4.35(0.74)$ & $4.37(0.70)$ & $4.39(0.79)$ & $4.30(0.81)$ \\
\hline \multicolumn{13}{|l|}{$50-60$} \\
\hline FIRNI & & 39 & & & & & & & & & & \\
\hline BFI & & 169 & & & & & & & & & & \\
\hline PAS & 164 & 179 & 302 & 2.81 & 4.39 & 4.16 & 5.04 & 5.0 & $4.44(0.74)$ & $4.31(0.72)$ & $4.47(0.73)$ & $4.33(0.80)$ \\
\hline
\end{tabular}

Note. $\quad$ FIRNI $=$ Five Individual Reaction Norms Inventory; BFI = Big Five Inventory; PAS $=$ Personality Adjective Scales

analyses are presented in Table 2. Figures 1-5 show the mean $T$ scores for each of the Big Five personality traits for each age group, separately for men and women, with fit curves from the regression models. For four traits, quadratic age effects met our criterion of $p<.01$. An examination of the mean FIRNI scores and the plotted fit curves from regression models in Figures $1-5$ shows that for most of the traits, the deviations from a simple linear trend were substantial; thus, more complex models sometimes contributed to a better description of age trends in the motivational manifestation of the Big Five. To facilitate an intuitive understanding of the magnitude of the age differences, we created five broader age groups (16- to 19-year-olds, 20- to 29-year-olds, 30- to 39-year-olds, 40- to 49-year-olds, 50- to 60-year-olds) and then identified the age group associated with the maximum score for each trait and the age group associated with the minimum score. Next, we computed the difference score between the two groups, expressed in age 30-34 $T$ units.

Neuroticism. Figure 1 shows the regression curves and the mean $T$ scores at each age for neuroticism, separately for men and women. We expected a negative association of neuroticism with age. In line with our hypothesis, older individuals tended to be less neurotic than younger individuals. Moreover, the quadratic model indicates that the negative relation between neuroticism and age was more pronounced in younger than in older age such that there was an almost medium difference (4.16 $T$ units) between the youngest age group and the 30- to 39-year-olds, whereas there was a small difference between the 30- to 39-year-olds and the oldest age group (2.44 $T$ units). Consistent with our hypothesis, women were more neurotic than men over the life span. In contrast to previous studies, we were not able to find an age by gender interaction effect with respect to FIRNI neuroticism.

Extraversion. For extraversion, our model selection criteria resulted in a quadratic model that best described the data. This model along with the observed extraversion mean $T$ scores is graphed in Figure 2. Results of the regression analysis indicated a negative association of extraversion with age in younger ages and a slight positive association in late middle adulthood. Comparing the mean $T$ scores of the five age groups, the results only reflect the negative association of extraversion with age such that the youngest group scored highest and the oldest group scored lowest. However, the difference was relatively small (3.27 $T$ units). These findings did not correspond with our hypothesis, which predicted a slight positive association of extraversion with age during adolescence. Regarding gender differences, women were consistently more extraverted than men. None of the age terms interacted with gender, suggesting that men and women did not show different age-related cross-sectional differences in extraversion.

Openness to experience. Of all five motivational manifestations of the Big Five, the largest age and gender effects were found for openness to experience. Data provided support for a quadratic model. The sample means and the quadratic fit line are plotted in Figure 3. Men and women showed a substantial positive association of openness with age throughout adolescence and younger adulthood, whereas age was negatively associated with openness during late middle adulthood. The mean $T$ scores of the five age groups demonstrate the positive association with age such that the youngest scores the lowest and the oldest group scores the highest (a difference of $6.32 T$ units). However, the largest difference was found between the two youngest age groups (3.69 $T$ units), while the three oldest age groups did not much differ $(0.93 T$ units between the 30 - to 39 -year-olds and the 50- to 60-year-olds). In line with our hypothesis, men were consistently higher in openness than women across the life span. Men and women did not differ in terms of the strength of the association of openness and age.

Agreeableness. For agreeableness, patterns of age differences were fairly linear (see Figure 4). A positive linear age trend is 


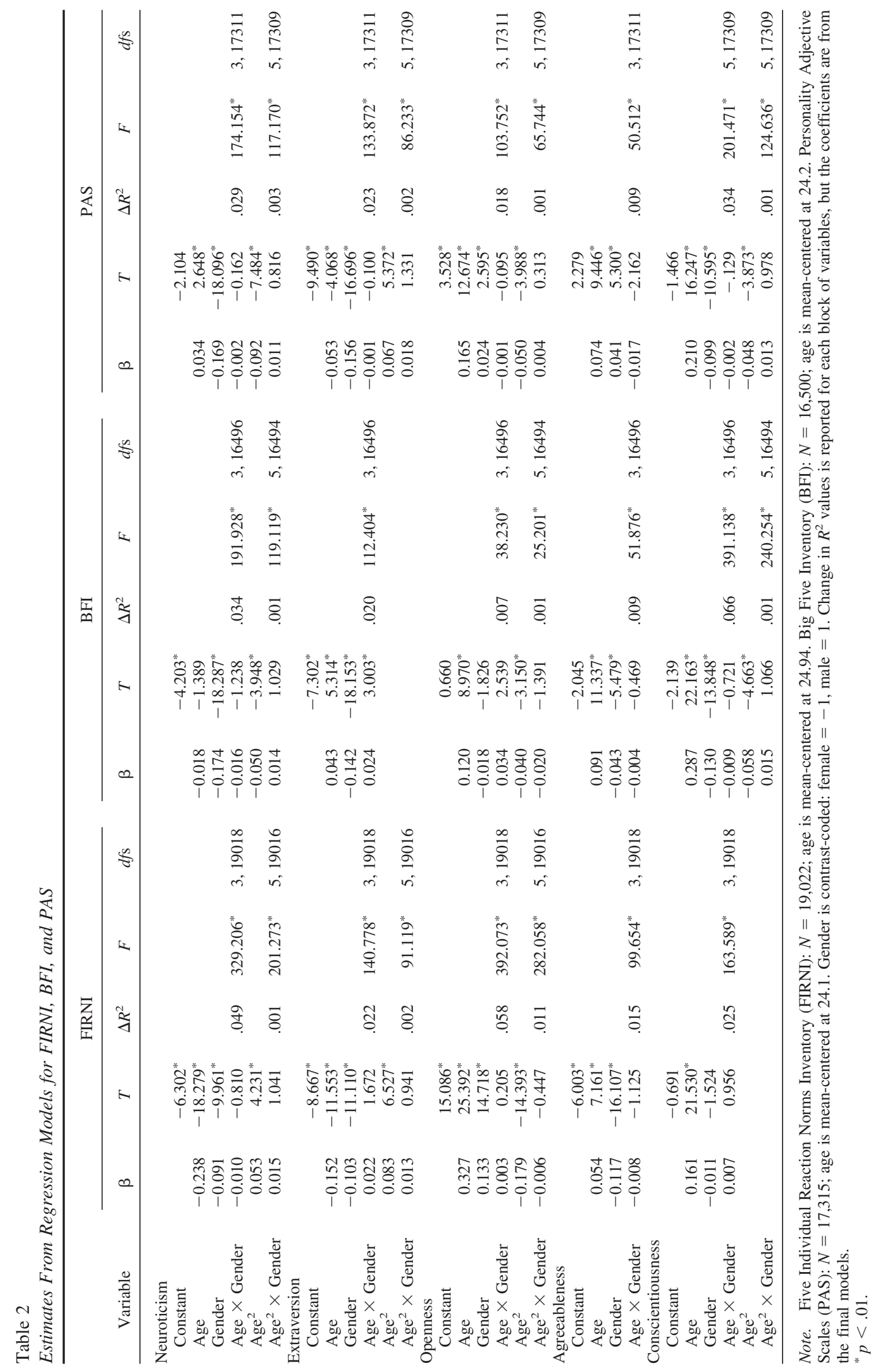



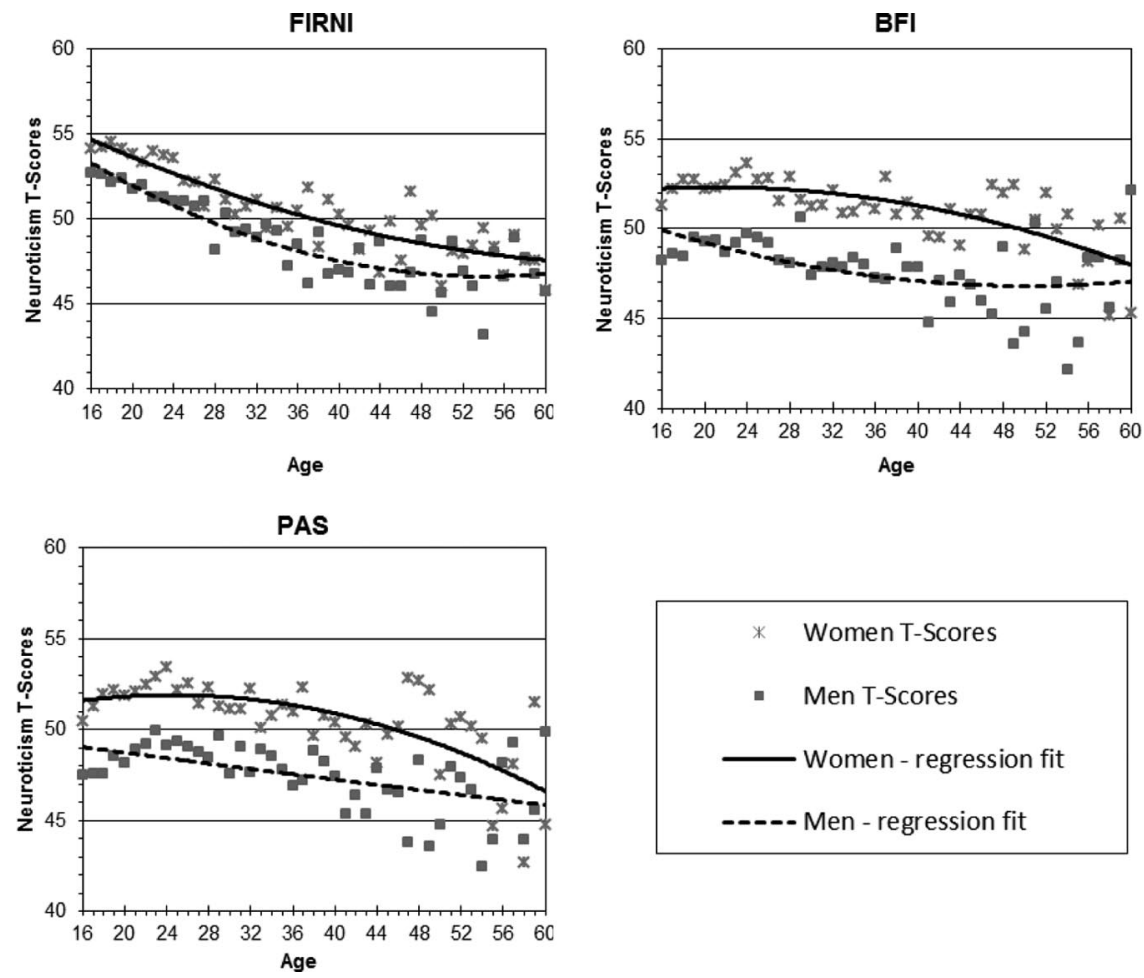

Figure 1. T scores for neuroticism broken down by age and gender, with fit curves from the regression models (see Table 1). FIRNI = Five Individual Reaction Norms Inventory; BFI = Big Five Inventory; PAS = Personality Adjective Scales.

consistent with the notion that people slightly increase in agreeableness at all ages. This result is consistent with previous developmental findings (see Roberts et al., 2006). In the present study, however, agreeableness showed the smallest age effect of all five motivational manifestations of the Big Five (difference of $1.53 T$ units between the youngest and the oldest age group). In contrast, agreeableness showed a relatively strong gender difference. Women were higher in agreeableness than men throughout adolescence and adulthood. We did not find an interaction of age and gender.

Conscientiousness. Results of regression analysis indicated a positive association of age and conscientiousness from age 16 to 60. The sample means and the linear fit line are plotted in Figure 5 . The close correspondence between the plotted function and the means from the $T$ scores suggests that the linear function captures the normative trend quite well. The difference between the youngest group and the oldest group was medium sized (5.95 $T$ units). Consistent with our hypothesis, the findings did not indicate a gender difference in this trait, nor did we find gender differences in the age correlates for conscientiousness.

\section{A Multimeasure Comparison of Age and Gender Differences in the Big Five}

Descriptive statistics of the raw scores of the BFI and PAS are presented in Table 1. Results of the regression analyses are shown in Table 2. In Figures 1-5, regression curves of the age and gender patterns in the motivational manifestations of the Big Five are displayed alongside the age and gender plots for the two traditional measures. Finally, correlations of the three personality measures, separately by age categories and gender, are provided in Table 3 .

Altogether, many age and gender patterns were replicated across measures. However, an examination of Figures 1-5 also reveals some interesting differences. In the motivational FIRNI scale, for instance, individuals showed a substantial negative association of neuroticism with age throughout adolescence and young adulthood. In the BFI and in the PAS, however, participants showed no association of neuroticism with age and a slight positive association, respectively, during younger ages and did not show a negative association until middle adulthood. Differences between the motivational manifestations and the traditional measures could be detected for extraversion as well. Specifically, a significant Age $\times$ Gender interaction in the BFI revealed that men showed a stronger positive association of extraversion with age compared to women across the life span, whereas in the motivational manifestations men and women did not differ in terms of the strength of the association: They showed a negative association of extraversion with age during younger ages, and a slight positive association in later middle adulthood. Regarding openness to experience, age differences were much more pronounced in the motivational manifestations (6.46 $T$ units between the highest and lowest scoring group) than in the traditional measures (PAS: $4.44 T$ units; BFI: $2.53 T$ units). Differences in gender patterns between the motivational manifestations and the traditional measures were most pronounced in agreeableness, with women being consistently more motivated to act in a cooperative way than men in situations of 



Figure 2. T scores for extraversion broken down by age and gender, with fit curves from the regression models (see Table 1). FIRNI = Five Individual Reaction Norms Inventory; BFI = Big Five Inventory; PAS = Personality Adjective Scales.

resource conflicts (i.e., the FIRNI conceptualization), whereas no corresponding gender differences were found for the other two traditional measures (in fact, young men were slightly higher in agreeableness than women in terms of the PAS). Finally, men and women did not differ in the motivational manifestations of conscientiousness, whereas in the traditional measures women were consistently more conscientious than men.

\section{Discussion}

The main objective of the present study was to investigate age and gender differences in the motivational manifestations of personality in a large, cross-sectional Internet sample with an age span of 16 to 60 years. This was the first study to investigate age and gender patterns in the motivational manifestations of the Big Five as measured with the FIRNI. In addition, we compared these patterns with age and gender patterns of two established instruments that are based on items that tap into descriptive correlates of the Big Five.

\section{Age and Gender Patterns in the Motivational Manifestations of the Big Five}

With this article we extend the motivational framework of the Big Five (Denissen \& Penke, 2008a) by adding a developmental perspective. Specifically, we present several socioemotional and biological arguments to justify our hypotheses regarding age and gender differences in the motivational manifestations of the Big Five. Overall, the present findings are consistent with our hypoth- eses and replicate previous research that used traditional Big Five measures (e.g., Lucas \& Donnellan, 2009; Roberts et al., 2006; Srivastava et al., 2003; Terracciano, McCrae, Brant, \& Costa, 2005; Soto et al., 2011). Specifically, these authors found negative age associations with extraversion and neuroticism, whereas they found agreeableness and conscientiousness to be positively related to age. Our results based on the FIRNI are also largely consistent with longitudinal findings showing that openness increases in late adolescence and young adulthood and decreases in late middle and older adulthood (cf. Roberts et al., 2006). Finally, we found that the negative association of FIRNI neuroticism with age gets weaker or even disappears in late middle adulthood. Although this pattern was not found in other studies, a recent study by Lehmann, Allemand, Zimprich, and Martin (2010) reported a similar increase in neuroticism in late midlife for another German-speaking sample.

Consistent with theoretical considerations and previous research, the positive association of agreeableness and conscientiousness with age and the negative association of neuroticism with age (except for late middle adulthood) can be interpreted as increasing maturity, in the sense of becoming emotionally more predictable and more attuned to social demands with age (e.g., Caspi, Roberts, \& Shiner, 2005; Helson \& Wink, 1987; Hogan \& Roberts, 2004; Roberts et al., 2008). This pattern of age differences in personality reflects enhancing maturity across adulthood. It contributes to everyday life running smoothly and maintaining or increasing subjective well-being, life success, and longevity (e.g., Roberts \& Wood, 2006). 

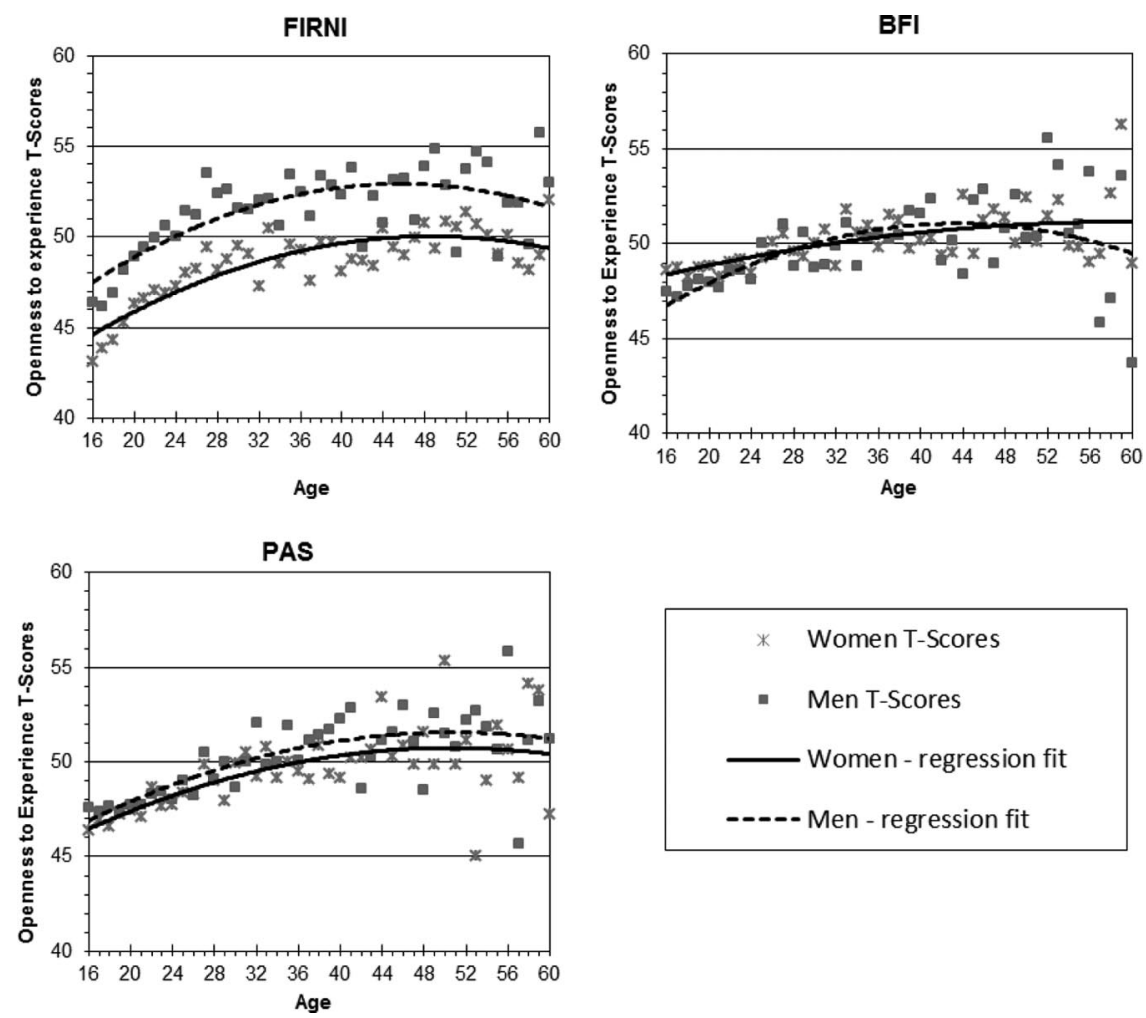

Figure 3. $T$ scores for openness to experience broken down by age and gender, with fit curves from the regression models (see Table 1). FIRNI = Five Individual Reaction Norms Inventory; BFI $=$ Big Five Inventory; PAS $=$ Personality Adjective Scales

Overall, using the FIRNI we replicated previous findings regarding gender patterns in the Big Five traits (except conscientiousness, see below; Lucas \& Donnellan, 2009; Schmitt et al., 2008; Srivastava et al., 2003). Specifically, our results suggest that women are generally more neurotic, extraverted, and agreeable but less open to experience than men. On the basis of a very large cross-cultural study, Lippa (2010) found that biological factors contribute to gender differences in personality. Because gender differences were consistent across 53 nations and tended not to be moderated by cultural indices of gender equality in this study, Lippa assumed that sociocultural factors play a negligible to small role in moderating gender differences. This conclusion fits well with our theoretical rationale, as most of our explanations for gender differences are based on the evolutionary principle of sexual selection (Buss, 1995). However, other studies (e.g., Costa et al., 2001; McCrae, Terracciano, \& 78 Members of the Personality Profiles of Cultures Project, 2005; Schmitt et al., 2008) have reported that gender differences were more pronounced in egalitarian societies. According to Schmitt et al. (2008), gender differences in personality are vulnerable to restraining environmental pressures. As a society becomes more prosperous and more egalitarian, heritable dispositional differences between men and women might be less constrained to develop and be perceived, resulting in a widening of the gap that exists between men and women in their personality trait ratings.

\section{A Multimeasure Comparison of Age and Gender Patterns in the Big Five}

To extend our analysis we aimed to compare age and gender patterns in motivational assessments of the Big Five traits with assessments of Big Five traits that have a descriptive background. As expected, similar age and gender patterns were found for all three. However, we also found distinct differences between the instruments that are consistent with the different theoretical conceptualization of the FIRNI when compared to the two other measures. First, regarding age patterns in personality, the largest difference across measures appeared in neuroticism. In the motivational manifestations of the Big Five as measured by the FIRNI, neuroticism was negatively associated with age during adolescence and young adulthood, whereas there was no association, or even a slightly positive relation, in late middle adulthood. The opposite pattern was found for the PAS and the BFI. Assessed with these scales, adolescents and young adults were stable in mean levels of neuroticism until middle adulthood and only started to decrease after that. The FIRNI conceptualization of neuroticism as sensitivity for social exclusion might account for these different age patterns, especially in adolescence and young adulthood (cf. Denissen \& Penke, 2008a, 2008b). Moreover, because correlates of neuroticism such as affect regulation and self-esteem tend to improve during late adolescence and young adulthood (John \& Gross, 2004; Robins, Trzesniewski, Tracy, Gosling, \& Potter, 



Figure 4. $T$ scores for agreeableness broken down by age and gender, with fit curves from the regression models $($ see Table 1 ). FIRNI = Five Individual Reaction Norms Inventory; BFI = Big Five Inventory; PAS = Personality Adjective Scales.

2002; Steinberg, 2005), it might be speculated that the FIRNI is more sensitive for developmental impulses in neuroticism during this age period than the traditional Big Five measures.

Second, we found larger age differences in openness to experience in the motivational manifestations compared to the traditional Big Five. Higher openness scores in middle-aged adults compared to adolescents and younger adults might reflect an increasing reward value of complex thought processes during this period. The positive association of openness to experience with age until relatively late in development (after which levels of openness drop again) could be due to an increasing level of self-efficacy regarding complex thought processes, due to practice over time. This positive development might be offset after middle age, when problems due to cognitive aging might surface and result in a lower reward value of engaging in complex and intellectually challenging thoughts.

Regarding gender patterns, the most notable differences between measures were found for conscientiousness. While the findings in the traditional measures were consistent with previous work favoring women (cf. Lucas \& Donnellan, 2009; Srivastava et al., 2003), men and women did not differ in conscientiousness in the motivational manifestations of the Big Five. The absence of gender differences in the motivational manifestations might express the conceptualization of conscientiousness as attention control in goal pursuit in the FIRNI. Empirical results suggest that women and men do not differ in cognitive control (Garavan et al., 2006; Luszczynska et al., 2004), which might reflect the ubiquitous importance of cognitive control processes in goal achieve- ment for both genders, regardless of gender differences in the content of these goals.

Overall, the use of the FIRNI seems to be associated with accentuated age trends in mean-level personality traits. These age and gender patterns are in accordance with socioemotional and biological principles. This is a first indication that the FIRNI should be more routinely included in assessments of personality development to more reliably pick up on these trends, though more research on the motivational manifestations of the Big Five is needed to substantiate such claims.

\section{Limitations}

Data were collected using the Internet. One problem of online surveys could be that they produce age-confounded sampling biases (Denissen, Neumann, \& van Zalk, 2010). For example, younger users might represent a fairly broad group, whereas middle-aged Internet users might be a more select subset of the corresponding population. First, to test for possible self-selection effects in the present sample, we compared the variability for the constructs of interest in the youngest and oldest age groups. If our oldest participants were indeed self-selected on the basis of their personality traits, then the observed variability of scores on those traits would be largest in adolescence and emerging adulthood (where age-specific samples would be most representative) and smallest in late middle adulthood (where age-specific samples would be most self-selected; see Soto et al., 2011). To identify 



Figure 5. $T$ scores for conscientiousness broken down by age and gender, with fit curves from the regression models $($ see Table 1). FIRNI = Five Individual Reaction Norms Inventory; BFI = Big Five Inventory; PAS = Personality Adjective Scales.

such trends, we computed a ratio for each scale (separately for men and women) that indexed the standard deviations in late middle adulthood (ages 50 to 60 ) relative to the standard deviation in adolescence (ages 16 to 19 ). Ratios substantially smaller than 1.00 would indicate much less variability in the oldest age group compared to the youngest age group. However, the mean ratio across personality traits, gender, and the three personality questionnaires was 0.93 . This ratio is relatively close to 1.00 and therefore suggests that the present findings are not likely due to differential self-selection effects, as these would lead to sample homogeneity in personality. Second, an age-confounded sampling bias would be supported if Internet usage is very dissimilar in the several age groups. However, survey research on Internet usage and age in Germany showed that $97 \%$ of the 16- to 24-year-olds use the Internet at least once a week, which is not much higher than the $93 \%$ of the 25 - to 44 -year-old age group or the $90 \%$ of the $45-$ to 64-year-old group (German Federal Office of Statistics, 2009). These statistics do not support the notion that older individuals in Germany have dramatically reduced access to the Internet, which reduces the likelihood that our older online participants somehow represent a more privileged or otherwise distinctive group.

Another concern regarding the design of our study is the crosssectional nature of the data. Age differences found in our analyses might be due to cohort (i.e., birth year) effects rather than to developmental change (e.g., Mroczek \& Spiro, 2003). However, research using cohort-sequential longitudinal data showed only very weak cohort differences in personality traits (Terracciano, McCrae, Brant, \& Costa, 2005). In addition, Trzesniewski and
Donnellan (2010) were using large samples of high school seniors from 1976 to 2006 and found little evidence of meaningful cohort change in variables like egotism, self-enhancement, individualism, self-esteem, locus of control, hopelessness, and loneliness. Moreover, McCrae et al. (1999) examined age differences in personality traits in Germany, Italy, Portugal, Croatia, and South Korea. They found similar patterns of age differences in each country, for both men and women. Because these nations differ substantially in culture and recent history, results mitigated the claim that history and cohort effects play an important role for personality development (McCrae et al., 1999). This is not to say that cohort is unimportant to age differences in the Big Five traits. For example, Roberts et al. (2006) showed in a meta-analysis that younger cohorts increased more in terms of conscientiousness than did older cohorts. Because longitudinal designs also cannot fully disentangle age and historical effects, comparisons between crosssectional and longitudinal studies across different cohorts likely provide the most insight into the age correlates of mean-level personality development. As previously noted, our cross-sectional findings converge with the findings of longitudinal research (Roberts et al., 2006; Terracciano et al., 2005).

Finally, it should be kept in mind that theorizing regarding the substantive nature of the Big Five and their developmental changes is still in its infancy. Although the FIRNI emphasizes motivational processes, individual differences in situational exposure and perceptions as well as individual abilities may also underlie personality variation. We hope that future research will help to disentangle the specific contributions of motivations and ability, while also 
Table 3

Correlations of the Three Personality Scales, by Age Category and Gender

\begin{tabular}{|c|c|c|c|c|c|c|c|c|c|c|}
\hline \multirow[b]{2}{*}{ Personality measure } & \multicolumn{2}{|c|}{ Age $16-19$} & \multicolumn{2}{|c|}{ Age $20-29$} & \multicolumn{2}{|c|}{ Age $30-39$} & \multicolumn{2}{|c|}{ Age $40-49$} & \multicolumn{2}{|c|}{ Age $50-60$} \\
\hline & Women & Men & Women & Men & Women & Men & Women & Men & Women & Men \\
\hline \multicolumn{11}{|l|}{ Neuroticism } \\
\hline FIRNI-BFI & .60 & .59 & .62 & .64 & .64 & .66 & .58 & .64 & .49 & .64 \\
\hline FIRNI-PAS & .63 & .62 & .64 & .67 & .66 & .69 & 62 & .63 & .51 & .64 \\
\hline BFI-PAS & .83 & .83 & .87 & .87 & .88 & .89 & .87 & .90 & .85 & .88 \\
\hline \multicolumn{11}{|l|}{ Extraversion } \\
\hline FIRNI-BFI & .77 & .76 & .76 & .79 & .74 & .75 & .74 & .80 & .74 & .83 \\
\hline FIRNI-PAS & .84 & .83 & .82 & .85 & .80 & .81 & .77 & .83 & .77 & .86 \\
\hline BFI-PAS & .88 & .87 & .88 & .90 & .87 & .88 & .86 & .88 & .81 & .89 \\
\hline \multicolumn{11}{|l|}{ Openness to experience } \\
\hline FIRNI-BFI & .61 & .60 & .59 & .59 & .61 & .60 & .63 & .64 & .58 & .68 \\
\hline FIRNI-PAS & .50 & .56 & .50 & .51 & .49 & .58 & .56 & .59 & .61 & .63 \\
\hline BFI-PAS & .64 & .69 & .68 & .67 & .67 & .71 & .69 & .70 & .67 & .78 \\
\hline \multicolumn{11}{|l|}{ Agreeableness } \\
\hline FIRNI-BFI & .59 & .62 & .53 & .58 & .48 & .55 & .45 & .54 & .65 & .60 \\
\hline FIRNI-PAS & .61 & .68 & .55 & .64 & .51 & .61 & .48 & .52 & .59 & .60 \\
\hline BFI-PAS & .77 & .79 & .76 & .76 & .74 & .76 & .73 & .71 & .75 & .77 \\
\hline \multicolumn{11}{|l|}{ Conscientiousness } \\
\hline FIRNI-BFI & .71 & .71 & .74 & .74 & .69 & .78 & .69 & .745 & .53 & .79 \\
\hline FIRNI-PAS & .51 & .53 & .55 & .57 & .47 & .62 & .47 & .54 & .35 & .55 \\
\hline BFI-PAS & .79 & .80 & .82 & .82 & .81 & .84 & .77 & .78 & .73 & .77 \\
\hline
\end{tabular}

Note. $\quad$ FIRNI $=$ Five Individual Reaction Norms Inventory; BFI $=$ Big Five Inventory; PAS $=$ Personality Adjective Scales.

taking into account additional constructs such as situational features, perceptions and attributions. In addition, future studies might examine additional motivational dimensions that do not map nicely on the Big Five (e.g., intrinsic motivation) as antecedents or consequences of personality development.

\section{Conclusions}

Our findings contribute to the literature by showing specific age and gender patterns in the Big Five, with a specific focus on their motivational manifestations. In many cases we replicated previous research on age and gender differences in personality traits. However, consistent with the motivational conceptualization of the FIRNI, we also found pronounced differences. The current study presents a broad theoretical rationale for age and gender differences in the motivational manifestations of the Big Five and first empirical evidence. Future studies on personality development should focus on the underlying socioemotional and biological processes in motivational manifestations of the Big Five, in addition to describing age differences in behavioral expressions.

\section{References}

Allemand, M., Zimprich, D., \& Hendriks, A. A. J. (2008). Age differences in five personality domains across the life span. Developmental Psychology, 44, 758-770. doi:10.1037/0012-1649.44.3.758

Ardila, A. (2008). On the evolutionary origins of executive functions. Brain and Cognition, 68, 92-99. doi:10.1016/j.bandc.2008.03.003

Baltes, P. B., Staudinger, U. M., \& Lindenberger, U. (1999). Lifespan psychology: Theory and application to intellectual functioning. Annual Review of Psychology, 50, 471-507. doi:10.1146/annurev .psych.50.1.471

Belle, D. (1991). Gender differences in the social moderators of stress. In
A. Monat \& R. S. Lazarus (Eds.), Stress and coping: An anthology (pp. 258-274). New York, NY: Columbia University Press.

Burnham, T. C. (2007). High-testosterone men reject low ultimatum game offers. Proceedings of the Royal Society: B. Biological Sciences, 274, 2327-2330. doi:10.1098/rspb.2007.0546

Buss, D. M. (1995). Psychological sex differences: Origins through sexual selection. American Psychologist, 50, 164-168. doi:10.1037/0003066X.50.3.164

Cacioppo, J. T., Petty, R. E., Feinstein, J. A., Blair, W., \& Jarvis, G. (1996). Dispositional differences in cognitive motivation: The life and times of individuals varying in need for cognition. Psychological Bulletin, 119, 197-253. doi:10.1037/0033-2909.119.2.197

Campbell, A. (2008). Attachment, aggression and affiliation: The role of oxytocin in female social behavior. Biological Psychology, 77, 1-10. doi:10.1016/j.biopsycho.2007.09.001

Carstensen, L. L., Isaacowitz, D. M., \& Charles, S. T. (1999). Taking time seriously: A theory of socioemotional selectivity. American Psychologist, 54, 165-181. doi:10.1037/0003-066X.54.3.165

Casey, B. J., Tottenham, N., Liston, C., \& Durston, S. (2005). Imaging the developing brain: What have we learned about cognitive development? Trends in Cognitive Sciences, 9, 104-110. doi:10.1016/j.tics.2005.01 .011

Caspi, A., \& Roberts, B. W. (2001). Personality development across the life course: The argument for change and continuity. Psychological Inquiry, 12, 49-66. doi:10.1207/S15327965PLI1202_01

Caspi, A., Roberts, B. W., \& Shiner, R. L. (2005). Personality development: Stability and change. Annual Review of Psychology, 56, 453-484. doi:10.1146/annurev.psych.55.090902.141913

Ceci, S. J., Williams, W. M., \& Barnett, S. M. (2009). Women's underrepresentation in science: Sociocultural and biological considerations. Psychological Bulletin, 135, 218-261. doi:10.1037/a0014412

Chapman, B. P., Duberstein, P. R., Sörensen, S., \& Lyness, J. M. (2007). Gender differences in Five Factor Model personality traits in an elderly cohort. Personality and Individual Differences, 43, 1594-1603. doi: 10.1016/j.paid.2007.04.028 
Charles, S. T., Reynolds, C. A., \& Gatz, M. (2001). Age-related differences and change in positive and negative affect over 23 years. Journal of Personality and Social Psychology, 80, 136-151. doi:10.1037/00223514.80.1.136

Cohen, J. (1988). Statistical power analysis for the behavioral sciences (2nd ed.). Hillsdale, NJ: Erlbaum.

Collins, W. A., \& Steinberg, L. (2006). Adolescent development in interpersonal context. In W. Damon, R. Lerner, \& N. Eisenberg (Eds.), Handbook of child psychology: Vol. 3. Social, emotional, and personality development (6th ed., pp. 1003-1067). New York, NY: Wiley.

Costa, P. T., Jr., \& McCrae, R. R. (1988). From catalog to classification: Murray's needs and the Five-Factor Model. Journal of Personality and Social Psychology, 55, 258-265. doi:10.1037/0022-3514.55.2.258

Costa, P. T., Jr., Terracciano, A., \& McCrae, R. R. (2001). Gender differences in personality traits across cultures: Robust and surprising findings. Journal of Personality and Social Psychology, 81, 322-331. doi:10.1037/0022-3514.81.2.322

Costa, P. T., Jr., Zonderman, A. B., McCrae, R. R., Cornoni-Huntley, J., Locke, B. Z., \& Barbano, H. E. (1987). Longitudinal analyses of psychological well-being in a national sample: Stability of mean levels. Journal of Gerontology, 42, 50-55.

Czeschlik, T., \& Nürk, H.-C. (1995). Shyness and sociability: Factor structure in a German sample. European Journal of Psychological Assessment, 11, 122-127. doi:10.1027/1015-5759.11.2.122

Davenport, E. C., Jr. (1990). Significance testing of congruence coefficients: A good idea? Educational and Psychological Measurement, 50, 289-296.

Denissen, J. J. A., Neumann, L., \& van Zalk, M. H. W. (2010). How the Internet is changing the implementation of traditional research methods, people's daily lives, and the way in which developmental scientists conduct research. International Journal of Behavioral Development, 34, 564-575. doi:10.1177/0165025410383746

Denissen, J. J. A., \& Penke, L. (2008a). Motivational individual reaction norms underlying the Five-Factor model of personality: First steps towards a theory-based conceptual framework. Journal of Research in Personality, 42, 1285-1302. doi:10.1016/j.jrp.2008.04.002

Denissen, J. J. A., \& Penke, L. (2008b). Neuroticism predicts reactions to cues of social inclusion. European Journal of Personality, 22, 497-517. doi:10.1002/per.682

Dingemanse, N. J., Kazern, A. J. N., Réale, D., \& Wright, J. (2010). Behavioural reaction norms: Animal personality meets individual plasticity. Trends in Ecology and Evolution, 25, 81-89. doi:10.1016/ j.tree.2009.07.013

Donnellan, M. B., \& Lucas, R. E. (2008). Age differences in the Big Five across the life span: Evidence from two national samples. Psychology and Aging, 23, 558-566. doi:10.1037/a0012897

Downey, G., Bonica, C., \& Rincon, C. (1999). Rejection sensitivity and adolescent romantic relationships. In W. Furman, B. Bradford Brown, \& C. Feiring (Eds.), The development of romantic relationships in adolescence (pp. 148-174). London, England: Cambridge University Press.

Eagly, A. (1987). Sex differences in social behavior: A social-role interpretation. Hillsdale, NJ: Erlbaum.

Eccles, J. S., Midgley, C., Wigfield, A., Buchanan, C. M., Reuman, D., Flanagan, C., \& Mac Iver, D. (1993). Development during adolescence: The impact of stage-environment fit on young adolescents' experiences in schools and in families. American Psychologist, 48, 90-101. doi: 10.1037/0003-066X.48.2.90

Feingold, A. (1994). Gender differences in personality: A meta-analysis. Psychological Bulletin, 116, 429-456. doi:10.1037/0033-2909.116.3 429

Garavan, H., Hester, R., Murphy, K., Fassbender, C., \& Kelly, C. (2006). Individual differences in the functional neuroanatomy of inhibitory control. Brain Research, 1105, 130-142. doi:10.1016/j.brainres .2006 .03 .029
German Federal Office of Statistics. (2009). Private Haushalte in der Informationsgesellschaft - Nutzung von Informations-und Kommunikationstechnologien [Private households in the information society: Use of information and communication technologies]. Wiesbaden, Germany: Author.

Giorgio, A., Watkins, K. E., Chadwick, M., James, S., Winmill, L., Douaud, G., . . James, A. C. (2010). Longitudinal changes in grey and white matter during adolescence. NeuroImage, 49, 94-103. doi:10.1016/ j.neuroimage.2009.08.003

Gridley, M. C. (2006). Cognitive styles partly explain gender disparity in engineering. American Psychologist, 61, 724-725. doi:10.1037/0003066X.61.7.72

Harman, H. H. (1976). Modern factor analysis. Chicago, IL: University of Chicago Press.

Hartup, W. W., \& Stevens, N. (1997). Friendships and adaptations in the life course. Psychological Bulletin, 121, 355-370. doi:10.1037/00332909.121.3.355

Havighurst, R. J. (1981). Developmental tasks and education (3rd ed.). New York, NY: Longman.

Heckhausen, J., Wrosch, C., \& Schulz, R. (2010). A motivational theory of life-span development. Psychological Review, 117, 32-60. doi:10.1037/ a0017668

Helson, R., \& Wink, P. (1987). Two conceptions of maturity examined in the findings of a longitudinal study. Journal of Personality and Social Psychology, 53, 531-541. doi:10.1037/0022-3514.53.3.531

Hogan, R., \& Roberts, B. W. (2004). A socioanalytic model of maturity. Journal of Career Assessment, 12, 207-217. doi:10.1177/ 1069072703255882

Ingles, C. J., La Greca, A. M., Marzo, J. C., Garcia-Lopez, L. J., \& Garcia-Fernandez, J. M. (2010). Social Anxiety Scale for adolescents: Factorial invariance and latent mean differences across gender and age in Spanish adolescents. Journal of Anxiety Disorders, 24, 847-855. doi:10.1016/j.janxdis.2010.06.007

Jang, K. L., Livesley, W. J., \& Vernon, P. A. (1998). A twin study of genetic and environmental contributions to gender differences in traits delineating personality disorder. European Journal of Personality, 12 , 331-344. doi:10.1002/(SICI)1099-0984(1998090)12:5<331::AID PER331>3.0.CO;2-D

John, O. P., Donahue, E. M., \& Kentle, R. L. (1991). The Big Five Inventory (Versions 4a and 54). Berkeley, CA: University of California, Berkeley, Institute of Personality and Social Research.

John, O. P., \& Gross, J. J. (2004). Healthy and unhealthy emotion regulation: Personality processes, individual differences, and life span development. Journal of Personality, 72, 1301-1333. doi:10.1111/j.14676494.2004.00298.x

John, O. P., Naumann, L. P., \& Soto, C. J. (2008). Paradigm shift to the integrative Big Five trait taxonomy: History, measurement, and conceptual issues. In O. P. John, R. W. Robins, \& L. A. Pervin (Eds.), Handbook of personality: Theory and research (3rd ed., pp. 114-158). New York, NY: Guilford Press.

Karp, D. A. (1987). Professionals beyond midlife: Some observations on work satisfaction in the fifty- to sixty-year decade. Journal of Aging Studies, 1, 209-223. doi:10.1016/0890-4065(87)90014-4

Kercher, A. J., Rapee, R. M., \& Schniering, C. A. (2009). Neuroticism, life events and negative thoughts in the development of depression in adolescent girls. Journal of Abnormal Child Psychology, 37, 903-915. doi:10.1007/s10802-009-9325-1

Kirsch, P., Esslinger, C., Chen, Q., Mier, D., Lis, S., Siddhanti, S., ... Meyer-Lindenberg, A. (2005). Oxytocin modulates neural circuitry for social cognition and fear in humans. Journal of Neuroscience, 25 , 11489-11493. doi:10.1523/JNEUROSCI.3984-05.2005

Klimstra, T. A., Hale, W. W., III, Raaijmakers, Q. A. W., Branje, S. J. T., \& Meeus, W. H. J. (2009). Maturation of personality in adolescence. 
Journal of Personality and Social Psychology, 96, 898-912. doi: $10.1037 / \mathrm{a} 0014746$

Kosfeld, M., Heinrichs, M., Zak, P. J., Fischbacher, U., \& Fehr, E. (2005). Oxytocin increases trust in humans. Nature, 435, 673-676. doi:10.1038/ nature 03701

Lang, F. R., Lüdtke, O., \& Asendorpf, J. B. (2001). Testgüte und psychometrische äquivalenz der deutschen Version des Big Five Inventory (BFI) bei jungen, mittelalten und alten Erwachsenen [Validity and psychometric equivalence of the German version of the Big Five Inventory in young, middle-aged, and old adults]. Diagnostica, 47, 111-121. doi:10.1026//0012-1924.47.3.111

Lehmann, R., Allemand, M., Zimprich, D., \& Martin, M. (2010). Persönlichkeitsentwicklung im mittleren Erwachsenenalter [Personality development in middle adulthood]. Zeitschrift für Entwicklungspsychologie und Pädagogische Psychologie, 42, 79-89. doi:10.1026/0049-8637/ a000008

Lippa, R. A. (2010). Sex-differences in personality traits and genderrelated occupational preferences across 53 nations: Testing evolutionary and social-environmental theories. Archives of Sexual Behavior, 39, 619-636. doi:10.1007/s10508-008-9380-7

Lucas, R. E., \& Donnellan, M. B. (2009). Age differences in personality: Evidence from a nationally representative Australian sample. Developmental Psychology, 45, 1353-1363. doi:10.1037/a0013914

Lüdtke, O., Trautwein, U., \& Husemann, N. (2009). Goal and personality trait development in a transitional period: Assessing change and stability in personality development. Personality and Social Psychology Bulletin, 35, 428-441. doi:10.1177/0146167208329215

Luszczynska, A., Diehl, M., Gutiérrez-Doña, B., Kuusinen, P., \& Schwarzer, R. (2004). Measuring one component of dispositional selfregulation: Attention control in goal pursuit. Personality and Individual Differences, 37, 555-566. doi:10.1016/j.paid.2003.09.026

Maccoby, E. E. (1990). Gender and relationships: A developmental account. American Psychologist, 45, 513-520. doi:10.1037/0003066X.45.4.513

Mazur, E. (1989). Predicting gender differences in same-sex friendships from affiliation motive and value. Psychology of Women Quarterly, 13, 277-291. doi:10.1111/j.1471-6402.1989.tb01002.x

McCrae, R. R., \& Costa, P. T., Jr. (1997). Conceptions and correlates of openness to experience. In R. Hogan, J. Johnson, \& S. Briggs (Eds.), Handbook of personality psychology (pp. 825-847). San Diego, CA: Academic.

McCrae, R. R., \& Costa, P. T., Jr. (2008). The Five-Factor theory of personality. In O. P. John, R. W. Robins, \& L. A. Pervin (Eds.), Handbook of personality: Theory and research (3rd ed., pp. 159-181). New York, NY: Guilford Press.

McCrae, R. R., Costa, P. T., Jr., de Lima, M. P., Simões, A., Ostendorf, F., Angleitner, A., . . Piedmont, R. L. (1999). Age differences in personality across the adult life span: Parallels in five cultures. Developmental Psychology, 35, 466-477. doi:10.1037/0012-1649.35.2.466

McCrae, R. R., Costa, P. T., Jr., Ostendorf, F., Angleitner, A., Høebíčková, M., Avia, M. D., .. . Smith, P. B. (2000). Nature over nurture: Temperament, personality, and life span development. Journal of Personality and Social Psychology, 78, 173-186. doi:10.1037/0022-3514.78.1.173

McCrae, R. R., Costa, P. T., Jr., Terracciano, A., Parker, W. D., Mills, C. J., De Fruyt, F., \& Mervielde, I. (2002). Personality trait development from age 12 to age 18: Longitudinal, cross-sectional, and cross-cultural analyses. Journal of Personality and Social Psychology, 83, 1456-1468. doi:10.1037/0022-3514.83.6.1456

McCrae, R. R., Terracciano, A., \& 78 Members of the Personality Profiles of Cultures Project. (2005). Universal features of personality traits from the observer's perspective: Data from 50 cultures. Journal of Personality and Social Psychology, 88, 547-561. doi:10.1037/0022-3514.88.3.547

Mroczek, D. K., \& Spiro, A., III. (2003). Modeling intraindividual change in personality traits: Findings from the normative aging study. The
Journals of Gerontology: Series B: Psychological Sciences and Social Sciences, 58, P153-P165. doi:10.1093/geronb/58.3.P153

Murray, H. (1938). Explorations in personality. New York, NY: Oxford University Press.

Nettle, D., \& Penke, L. (2010). Personality: Bridging the literatures from human psychology and behavioural ecology. Philosophical Transactions of the Royal Society of London: Series B, Biological Sciences, 365, 4043-4050. doi:10.1098/rstb.2010.0061

Ostendorf, F. (1990). Sprache und Persönlichkeitsstruktur: Zur Validität des Fünf-Faktoren-Modells der Persönlichkeit [Language and personality structure: On the validity of the five-factor model of personality]. Regensburg, Germany: Roderer.

Paus, T. (2005). Mapping brain maturation and cognitive development during adolescence. Trends in Cognitive Sciences, 9, 60-68. doi: 10.1016/j.tics.2004.12.008

Penke, L. (2010). Bridging the gap between modern evolutionary psychology and the study of individual differences. In D. M. Buss \& P. H. Hawley (Eds.), The evolution of personality and individual differences (pp. 243-279). New York, NY: Oxford University Press. doi:10.1093/ acprof:oso/9780195372090.003.0009

Penke, L., Denissen, J. J. A., \& Miller, G. F. (2007a). The evolutionary genetics of personality. European Journal of Personality, 21, 549-587. doi:10.1002/per.629

Penke, L., Denissen, J. J. A., \& Miller, G. F. (2007b). Evolution, genes, and inter-disciplinary personality research. European Journal of Personality, 21, 639-665. doi:10.1002/per.657

Piaget, J. (1983). Piaget's theory. In P. H. Mussen (Ed.), Handbook of child psychology: Vol. 1. History, theory, and methods (pp. 103-128). New York, NY: Wiley.

Riediger, M., Freund, A. M., \& Baltes, P. B. (2005). Managing life through personal goals: Intergoal facilitation and intensity of goal pursuit in younger and older adulthood. The Journals of Gerontology, Series B: Psychological Sciences and Social Sciences, 60, P84-P91. doi:10.1093/ geronb/60.2.P84

Roberts, B. W. (2007). Contextualizing personality psychology. Journal of Personality, 75, 1071-1082. doi:10.1111/j.1467-6494.2007.00467.x

Roberts, B. W., Walton, K. E., \& Viechtbauer, W. (2006). Patterns of mean-level change in personality traits across the life course: A metaanalysis of longitudinal studies. Psychological Bulletin, 132, 1-25. doi 10.1037/0033-2909.132.1.1

Roberts, B. W., \& Wood, D. (2006). Personality development in the context of the neo-socioanalytic model of personality. In D. Mroczek \& T. Little (Eds.), Handbook of personality development (pp. 11-39). Mahwah, NJ: Erlbaum.

Roberts, B. W., Wood, D., \& Caspi, A. (2008). The development of personality traits in adulthood. In O. P. John, R. W. Robins, \& L. A. Pervin (Eds.), Handbook of personality: Theory and research (3rd ed., pp. 375-398). New York, NY: Guilford Press.

Robins, R. W., Trzesniewski, K. H., Tracy, J. L., Gosling, S. D., \& Potter, J. (2002). Global self-esteem across the lifespan. Psychology and Aging, 17, 423-434. doi:10.1037/0882-7974.17.3.423

Rogers, G. M., Park, J.-H., Essex, M. J., Klein, M. H., Silva, S. G., Hoyle, R. H., .. March, J. S. (2009). The Dysfunctional Attitudes Scale: Psychometric properties in depressed adolescents. Journal of Clinical Child and Adolescent Psychology, 38, 781-789. doi:10.1080/ 15374410903259007

Rubia, K., Smith, A. B., Woolley, J., Nosarti, C., Heyman, I., Taylor, E., \& Brammer, M. (2006). Progressive increase of frontostriatal brain activation from childhood to adulthood during event-related tasks of cognitive control. Human Brain Mapping, 27, 973-993. doi:10.1002/ hbm.20237

Schmithorst, V. J., Wilke, M., Dardzinski, B. J., \& Holland, S. K. (2005). Cognitive functions correlate with white matter architecture in a normal 
pediatric population: A diffusion tensor MRI study. Human Brain Mapping, 26, 139-147. doi:10.1002/hbm.20149

Schmitt, D. P. (2004). The Big Five related to risky sexual behavior across 10 world regions: Differential personality associations of sexual promiscuity and relationship infidelity. European Journal of Personality, 18, 301-319. doi:10.1002/per.520

Schmitt, D. P., Realo, A., Voracek, M., \& Allik, J. (2008). Why can't a man be more like a woman? Sex differences in Big Five personality traits across 55 cultures. Journal of Personality and Social Psychology, 94, 168-182. doi:10.1037/0022-3514.94.1.168

Solnick, S. (2001). Gender differences in the ultimatum game. Economic Inquiry, 39, 189-200. doi:10.1093/ei/39.2.189

Soto, C. J., John, O. P., Gosling, S. D., \& Potter, J. (2011). Age differences in personality traits from 10 to 65: Big Five domains and facets in a large cross-sectional sample. Journal of Personality and Social Psychology, 100, 330-348. doi:10.1037/a0021717

Spelke, E. S., \& Grace, A. D. (2006). Abilities, motives, and personal styles. American Psychologist, 61, 725-726. doi:10.1037/0003066X.61.7.725

Srivastava, S., John, O. P., Gosling, S. D., \& Potter, J. (2003). Development of personality in early and middle adulthood: Set like plaster or persistent change? Journal of Personality and Social Psychology, 84, 1041-1053. doi:10.1037/0022-3514.84.5.1041

Steinberg, L. (2005). Cognitive and affective development in adolescence. Trends in Cognitive Sciences, 9, 69-74. doi:10.1016/j.tics.2004.12.005

Steinberg, L. (2007). Risk taking in adolescence: New perspectives from brain and behavioral science. Current Directions in Psychological Science, 16, 55-59. doi:10.1111/j.1467-8721.2007.00475.x

Steinberg, L., \& Monahan, K. C. (2007). Age differences in resistance to peer influence. Developmental Psychology, 43, 1531-1543. doi: 10.1037/0012-1649.43.6.1531

Steinberg, L., \& Silverberg, S. B. (1986). The vicissitudes of autonomy in early adolescence. Child Development, 57, 841-851. doi:10.2307/ 1130361

Szolnoki, A., Perc, M., Szabo, G., \& Stark, H.-U. (2009). Impact of aging on the evolution of cooperation in the spatial prisoner's dilemma game. Physical Review E: Statistical, Nonlinear, and Soft Matter Physics, 80, 021901. doi:10.1103/PhysRevE.80.021901

Tamnes, C. K., Ostby, Y., Fjell, A. M., Westlye, L. T., Due-Tonnessen, P.,
\& Walhovd, K. B. (2010). Brain maturation in adolescence and young adulthood: Regional age-related changes in cortical thickness and white matter volume and microstructure. Cerebral Cortex, 20, 534-548. doi: 10.1093/cercor/bhp118

Tau, G. Z., \& Peterson, B. S. (2010). Normal development of brain circuits. Neuropsychopharmacology, 35, 147-168. doi:10.1038/npp.2009.115

Taylor, S. E., Klein, L. C., Lewis, B. P., Gruenewald, T. L., Gurung, R. A. R., \& Updegraff, J. A. (2000). Biobehavioral responses to stress in females: Tend-and-befriend, not fight-or-flight. Psychological Review, 107, 411-429. doi:10.1037/0033-295X.107.3.411

Terracciano, A., Costa, P. T., Jr., \& McCrae, R. R. (2006). Personality plasticity after age 30. Personality and Social Psychology Bulletin, 32, 999-1009. doi:10.1177/0146167206288599

Terracciano, A., McCrae, R. R., Brant, L. J., \& Costa, P. T., Jr. (2005) Hierarchical linear modeling analyses of the NEO-PI-R Scales in the Baltimore Longitudinal Study of Aging. Psychology and Aging, 20, 493-506. doi:10.1037/0882-7974.20.3.493

Trzesniewski, K. H., \& Donnellan, B. M. (2010). Rethinking "Generation me": A study of cohorts effects from 1976-2006. Perspectives on Psychological Science, 5, 58-75. doi:10.1177/1745691609356789

Tucker, L. R. (1951). A method for synthesis of factor analytic studies (Personnel Research Section Report No. 984). Washington, DC: Department of the Army.

van Aken, M. A. G., Denissen, J. J. A., Branje, S. J. T., Dubas, J. S., \& Goossens, L. (2006). Midlife concerns and short-term personality change in middle adulthood. European Journal of Personality, 20, 497-513. doi:10.1002/per.603

Winter, D. G., John, O. P., Stewart, A. J., Klohnen, E. C., \& Duncan, L. E. (1998). Traits and motives: Toward an integration of two traditions in personality research. Psychological Review, 105, 230-250. doi:10.1037/ 0033-295X.105.2.230

Wischniewski, J., Windmann, S., Juckel, G., \& Brüne, M. (2009). Rules of social exchange: Game theory, individual differences and psychopathology. Neuroscience and Biobehavioral Reviews, 33, 305-313. doi: 10.1016/j.neubiorev.2008.09.008

Wong, M. M., \& Csikszentmihalyi, M. (1991). Affiliation motivation and daily experience: Some issues on gender differences. Journal of Personality and Social Psychology, 60, 154-164. doi:10.1037/00223514.60.1.154 


\section{Appendix}

\section{Five Individual Reaction Norms Inventory (FIRNI)}

\begin{tabular}{|c|c|c|c|c|c|}
\hline & $\begin{array}{l}\text { strongly } \\
\text { disagree }\end{array}$ & disagree & $\begin{array}{l}\text { neither agree } \\
\text { nor disagree }\end{array}$ & agree & $\begin{array}{l}\text { strongly } \\
\text { agree }\end{array}$ \\
\hline \multirow{2}{*}{\multicolumn{6}{|c|}{$\begin{array}{l}\text { Interacting with people generally gives me a lot of energy } \\
\text { I seldom fear that other people may not like me }\end{array}$}} \\
\hline & & & & & \\
\hline \multicolumn{6}{|l|}{ I enjoy thinking of new ways to solve problems } \\
\hline \\
\hline \multicolumn{6}{|l|}{$\begin{array}{l}\text { I would rather share something than to compete with other } \\
\text { people for having it all myself }\end{array}$} \\
\hline \multicolumn{6}{|l|}{ I feel best when I am alone } \\
\hline \multicolumn{6}{|l|}{$\begin{array}{l}\text { When I meet with friends I sometimes have the feeling } \\
\text { that they talk badly about me afterwards }\end{array}$} \\
\hline \multicolumn{6}{|l|}{ For me, thinking is not connected with fun } \\
\hline \multicolumn{6}{|l|}{ When I have a plan I do everything to achieve it } \\
\hline \multicolumn{6}{|l|}{$\begin{array}{l}\text { My own well-being is more important to me than the } \\
\text { problems of other people }\end{array}$} \\
\hline \multicolumn{6}{|l|}{ I like to meet a lot of people and have fun with them } \\
\hline \multicolumn{6}{|l|}{ I never doubt that I deserve to be accepted by others } \\
\hline \multicolumn{6}{|l|}{$\begin{array}{l}\text { I like to think about how society could look like in the } \\
\text { future }\end{array}$} \\
\hline \multicolumn{6}{|l|}{$\begin{array}{l}\text { When I encounter difficulties in implementing a plan I } \\
\text { tend to give up quickly }\end{array}$} \\
\hline \multicolumn{6}{|l|}{ I'd rather put aside my own interests when they conflict } \\
\hline \multicolumn{6}{|l|}{$\begin{array}{l}\text { When I am together with a lot of people I prefer to stay in } \\
\text { the background }\end{array}$} \\
\hline \multicolumn{6}{|l|}{$\begin{array}{l}\text { I often have doubts about the stability of my social } \\
\text { relationships }\end{array}$} \\
\hline \multicolumn{6}{|l|}{ I don't like to think about things when there is no clear } \\
\hline \multicolumn{6}{|l|}{$\begin{array}{l}\text { I would not have a problem working hard for something } \\
\text { that only pays off after a relatively long time }\end{array}$} \\
\hline \multicolumn{6}{|l|}{ I am reluctant to help other people if that leads to } \\
\hline Talking with other people motivates me and brings out the & & & & & \\
\hline $\begin{array}{l}\text { Even when friends or relatives do not call me for a long } \\
\text { time, I do not assume it is my fault }\end{array}$ & & & & & \\
\hline $\begin{array}{l}\text { I love to think about complex issues such as the purpose } \\
\text { of life or world affairs }\end{array}$ & & & & & \\
\hline I often do not implement my plans to the end & & & & & \\
\hline \multicolumn{6}{|l|}{ I like to be generous without expecting a service in return } \\
\hline \multicolumn{6}{|l|}{ I usually prefer to do things alone } \\
\hline \multicolumn{6}{|l|}{ When I do not hear from a person for a long time I } \\
\hline \multicolumn{4}{|l|}{ I don't like to engage in thought experiments } & & \\
\hline $\begin{array}{l}\text { When I am acting on a plan I do not easily let myself be } \\
\text { distracted by short-term needs }\end{array}$ & & & & & \\
\hline $\begin{array}{l}\text { In conflicts of interest with others, I always try to take out } \\
\text { the maximum for myself }\end{array}$ & & & & & \\
\hline I always find it fun to meet new people & & & & & \\
\hline $\begin{array}{l}\text { If a person who is important to me somehow behaves } \\
\text { strangely, I seldom presume that this is related to me }\end{array}$ & & & & & \\
\hline I really like to engage in mental activity & & & & & \\
\hline
\end{tabular}


Appendix (continued)

\begin{tabular}{|c|c|}
\hline $\begin{array}{l}\text { rongly } \\
\text { sagree }\end{array}$ & ee \\
\hline
\end{tabular}

disagree disagree nor disagree agree agree

I have often set myself a goal without really trying to reach it

When I share something with others I don't mind if others get more than I

Being with other people is often exhausting for me

If other people signal that they do not like something about me, my mood can quickly become clouded

I'd rather occupy myself with daily things than think about theoretical problems

When I have set myself a goal I pursue it very persistently

I don't like to do someone a favor when I know he or she will not give me something back in the future

I feel best when I have a lot of people around me

When friends or relatives do not give me enough attention, I seldom have the feeling that they do not like me anymore

I feel best when I am intellectually challenged

It is very difficult for me to follow a plan if it requires setting aside my momentary concerns

I would also help other people when I am having serious problems of my own

I do not quickly get enthusiastic about other people

When I pick up signs of rejection by other people, I am immediately alarmed and speculate about the possible cause

I don't like to think about unconventional ideas

When I have gotten a plan into my head, I stick to it, no matter how long it takes

I would not have a problem asserting my own interests at the expense of other people

\begin{tabular}{lllll}
0 & 0 & 0 & 0 & 0 \\
0 & 0 & 0 & 0 & 0 \\
0 & 0 & 0 & 0 & 0 \\
0 & 0 & 0 & 0 & 0 \\
0 & 0 & 0 & 0 & 0 \\
0 & 0 & 0 & 0 & 0 \\
0 & 0 & 0 & 0 & 0 \\
0 & 0 & 0 & 0 & 0 \\
0 & 0 & 0 & 0 & 0 \\
0 & 0 & 0 & 0 & 0 \\
0 & 0 & 0 & 0 & 0 \\
0 & 0 & 0 & 0 & 0 \\
0 & 0 & 0 & 0 & 0 \\
0 & 0 & 0 & 0 & 0 \\
0 & 0 & 0 & 0 & 0 \\
0 & 0 & 0 & 0 & 0 \\
0 & 0 & 0 & 0 & 0 \\
\hline
\end{tabular}

Note. From "Motivational Individual Reaction Norms Underlying the Five-Factor Model of Personality: First Steps Towards A Theory-Based Conceptual Framework," by J. J. A. Denissen and L. Penke, 2008, Journal of Research in Personality, 42, p. 1299. Copyright 2008 by Elsevier.

Received July 12, 2010

Revision received December 16, 2011

Accepted December 19, 2011 